\title{
QUALIDADE DE SEMENTES DE MILHO NAS SECAGENS INTERMITENTE RÁPIDA E CONTÍNUA COM ALTAS TEMPERATURAS
}

\author{
Samira O.M. EI TASSA-COLODEL ${ }^{1}$ \\ Dirk Claudio AHRENS ${ }^{2}$ \\ Luiz DONI FILHO3 \\ Alberto Sérgio do Rego BARROS ${ }^{4}$
}

\begin{abstract}
RESUMO
A procura por sementes de milho tem crescido nos últimos anos pela expansão do cultivo. As sementes vêm úmidas do campo havendo necessidade de secá-las a granel até $13 \%$, que é realizado tradicionalmente com temperaturas que não excedem $40^{\circ} \mathrm{C}$ no ar de secagem. Dessa forma, o objetivo deste trabalho foi o de estudar a eficiência de secadores intermitente rápido e de fluxo contínuo na secagem de sementes de milho variedade, empregando-se altas temperaturas, e avaliando-se a qualidade física, fisiológica e sanitária. Assim, dois lotes de sementes de milho IAPAR 51 foram submetidos a dois secadores: a) intermitente rápido, com $60^{\circ} \mathrm{C}$ na câmara inferior; b) fluxo contínuo, empregando $60^{\circ} \mathrm{C}$ (câmara superior) e $50^{\circ} \mathrm{C}$ (inferior). As amostras de sementes, retiradas durante o processo de secagem, foram avaliadas pelos testes de germinação, frio sem solo (vigor); sanidade, pureza e danos mecânicos, em julho e outubro de 1996. As velocidades de secagem foram de 1,1 $\mathrm{pph}^{-1} \mathrm{para}^{-1}$ o secador contínuo e $0,9 \mathrm{pph}^{-1}$ para o intermitente rápido. Conclui-se: a) os secadores intermitente rápido e de fluxo contínuo são eficientes na secagem de milho com altas temperaturas; b) não há comprometimento das qualidades física e fisiológica das sementes submetidas à secagem contínua e intermitente rápida, empregando-se as temperaturas no ar de secagem de $60^{\circ} \mathrm{C} e$ $60 / 50^{\circ} \mathrm{C}$, respectivamente; c) nas temperaturas utilizadas, os processos de secagem não reduzem a infestação de Penicillium.
\end{abstract}

PALAVRAS-CHAVE: Zea mays L., germinação, vigor, Penicillium spp., Aspergillus spp., velocidade de secagem

\section{CORN SEED QUALITY IN FAST INTERMITTENT AND IN CONTINUOUS DRYING WITH HIGH TEMPERATURES}

\begin{abstract}
The corn seed demand has grown in the last years because of the planting expansion. The seeds come from the field with high moisture and need to be bulk dried to $13 \%$. The drying procedure is accomplished traditionally with temperatures that do not exceed $40^{\circ} \mathrm{C}$ in the drying air. The objective of this work was to study the efficiency of dryers with fast intermittent and with continuous flow in drying of corn variety seeds, using high temperatures. It was evaluated the physical, physiologic and sanitary quality of the seeds. Two lots of IAPAR 51 seed corn were submitted to two dryers: a) fast intermittent, with $60^{\circ} \mathrm{C}$ in the inferior camera; b) continuous flow, using $60^{\circ} \mathrm{C}$ (superior camera) and $50^{\circ} \mathrm{C}$ (inferior). The seeds samples, took during the drying process, were submitted to germination tests, cold without soil (vigor); sanity, purity and mechanical damages, in July and October of 1996. The drying speed was of $1.1 \mathrm{pph}^{-1}$ on the continuous dryer and of $0.9 \mathrm{pph}^{-1}$ on the fast intermittent dryer. The conclusions are: a) the fast intermittent and the continuous flow dryers are efficient in corn drying with high temperatures; $b$ ) the fast intermittent and the continuous drying does not affect the physical and physiological quality of the seeds with the $60^{\circ} \mathrm{C}$ and $60 / 50^{\circ} \mathrm{C}$ temperatures in the air drying, respectively; c) the Penicillium infection is not reduced with the temperatures used in the drying processes.
\end{abstract}

KEY WORS: Zea mays L., germination, vigor, Penicillium spp., Aspergillus spp., drying speed

\footnotetext{
${ }^{1}$ Eng. Agra . Prof. MSc. Escola Técnica de Cuiabá, MT., e-mail: moleta@zaz.com.br

2 Eng. Agro. Pesq. Dr. IAPAR, C.P. 129, CEP 84001-970, Ponta Grossa, PR., e-mail: dahrens@pr.gov.br

${ }^{3}$ Eng. Agr ${ }^{\circ}$. Prof. Dr. Universidade Federal do Paraná, Setor de Ciências Agrárias, e-mail: doni@agrarias.ufpr.br

${ }^{4}$ Eng. Agr ${ }^{\circ}$. Pesq. MSc. IAPAR, C.P. 481, CEP 86001-970, Ponta Grossa, PR., e-mail: asbarros@pr.gov.br
} 


\section{INTRODUÇÃO}

A colheita das sementes é uma operação diretamente relacionada aos resultados qualitativos e quantitativos obtidos na produção. As sementes, nesta ocasião, nem sempre se encontram com teores de água compatíveis com os demandados para a conservação, levando a considerar a secagem como operação que merece destaque dentro do processo de produção (Ahrens e Peske, 1; Villela, 17).

A permanência das sementes, com elevados teores de água, durante o período compreendido entre a colheita e a secagem, contribui para acelerar o processo de deterioração devido à elevada atividade metabólica que, além de consumir as substâncias de reserva, libera energia e água favorecendo $o$ desenvolvimento de microrganismos e insetos (Villela, 17).

$\mathrm{Na}$ secagem de sementes, pelo processo intermitente de fornecimento de calor, elas são submetidas a alternâncias nos períodos de contato com o ar aquecido e o ar ambiente. Este processo pode ser considerado lento, quando o período de contato do ar aquecido é superior ao tempo de exposição com ar frio, ou rápido, na situação inversa (Ahrens et al., 2; Ahrens e Villela, 4). Ressalta-se, que na secagem intermitente, a migração da água, do interior para a superfície da semente, é desacelerada durante o período de ação do ar não aquecido (Puzzi, 15).

É possível a utilização do secador intermitente como de fluxo contínuo, empregando ar aquecido nas duas câmaras de secagem, de modo que o fornecimento do ar quente seja interrompido apenas durante a movimentação ascendente pelo elevador (Ahrens e Lollato, 3; Villela, 17).

Durante a secagem os danos às sementes dependem das interações entre a temperatura do ar, o tempo de exposição à alta temperatura e a umidade da semente. Estes danos são representados por rachaduras internas, rompimento e descoloração do tegumento, produção de plântulas anormais e perda da viabilidade (Nellist e Hughes, 12). Observou-se também um aumento linear nos danos mecânicos, especialmente quando utilizadas altas temperaturas $\left(50-90^{\circ} \mathrm{C}\right)$ do ar de secagem (Pereira, 13). Por outro lado, demonstrouse que a secagem contínua adaptada não causa efeitos prejudiciais à qualidade fisiológica de sementes de milho (Villela, 17).

As rachaduras, provocadas pela secagem, podem servir como porta de entrada para microrganismos, representados principalmente pelos gêneros Aspergillus e Penicillium, associados ao processo de deterioração das sementes (Wetzel, 19). Constatou-se que a secagem intermitente de sementes de milho proporcionou vantagens fisiológicas e sanitárias quando comparada à secagem realizada com fornecimento contínuo de calor (Gustafson e Morey, 8). Também a presença do Penicillium spp., pode ser reduzida com o emprego do secador contínuo adaptado (Villela,17).
Dessa forma, o objetivo deste trabalho foi o de estudar a eficiência de secadores intermitente rápido e de fluxo contínuo na secagem de sementes de milho variedade, empregando altas temperaturas, avaliando-se as qualidades física, fisiológica e sanitária. 


\section{MATERIAL E MÉTODOS}

Foram empregados dois lotes de sementes de milho variedade, cultivar IAPAR 51, colhidos a granel no mês de maio de 1996 com colhedeira automotriz. Utilizaram-se as instalações das Unidades de Beneficiamento de Sementes da Companhia de Desenvolvimento Agropecuário do Paraná e do Instituto Agronômico do Paraná IAPAR, ambas no município de Ponta Grossa/PR. Cada lote, após processamento em máquina de pré-limpeza, foi destinado à aplicação dos seguintes tratamentos:

\section{Secagem intermitente rápida (IR):}

Foi empregado um secador, de marca "Moreira", com capacidade estática de quatro toneladas $(0,4$ t na câmara de secagem inferior e 3,6 t na câmara de equalização superior), razão de intermitência de 1:9, provido de elevador de canecas (descarga centrífuga) alimentado por transportador vibratório.

A secagem, conduzida durante 240 minutos, foi acompanhada por amostragens no secador (FIGURA 1) a cada trinta minutos (teor de água e temperatura das sementes no ponto 2) e sessenta minutos (no ponto 2: qualidade física, fisiológica e sanitária). A temperatura inicial do ar foi de $20^{\circ} \mathrm{C}$ e chegando ao máximo de $60^{\circ} \mathrm{C}$ (no ponto 1 controlado por termômetro), sem exceder $44,5^{\circ} \mathrm{C}$ na massa de sementes.

As temperaturas do ar de secagem foram monitoradas com um termômetro fixo na entrada do ar quente no secador, conforme consta na FIGURA 1, ponto (1).

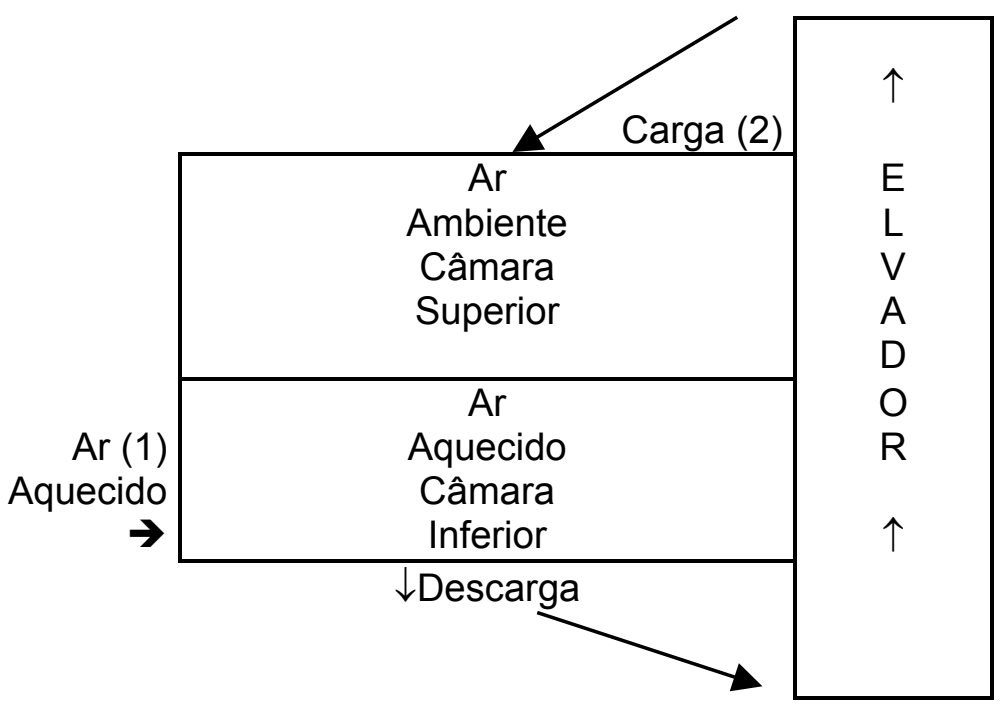

FIGURA 1 - Secagem intermitente rápida: esquema operacional do secador utilizado e dos pontos de amostragem.

\section{Secagem contínua (C):}

Foi utilizado um secador de fluxo contínuo (ar aquecido a $60^{\circ} \mathrm{C}$ na entrada de ar da câmara superior e câmara inferior a $50^{\circ} \mathrm{C}$, de modo que o resfriamento das sementes ocorria na movimentação ascendente pelo elevador), denominado comercialmente de "KW15", com capacidade estática de 15 toneladas, (10 t na câmara de secagem superior e $5 \mathrm{t}$ na câmara de equalização inferior), descarga por rosca sem-fim alimentando elevador de canecas com descarga centrífuga.
As temperaturas do ar de secagem foram monitoradas com um termômetro fixo na entrada do ar quente no secador, conforme consta na FIGURA 2, pontos 1 e 2 .

A secagem, conduzida durante 270 minutos, foi acompanhada por amostragens no secador (FIGURA 2) a cada $45 \mathrm{~min}$. (temperatura do ar nos pontos 1 e 2, temperatura da massa de ar nos pontos 3 e 4) e noventa minutos (qualidade física, fisiológica e sanitária no ponto 4). A temperatura inicial do ar foi de $20^{\circ} \mathrm{C}$ e chegando ao máximo de $60^{\circ} \mathrm{C}$, sem exceder $50^{\circ} \mathrm{C}$ na massa de sementes.

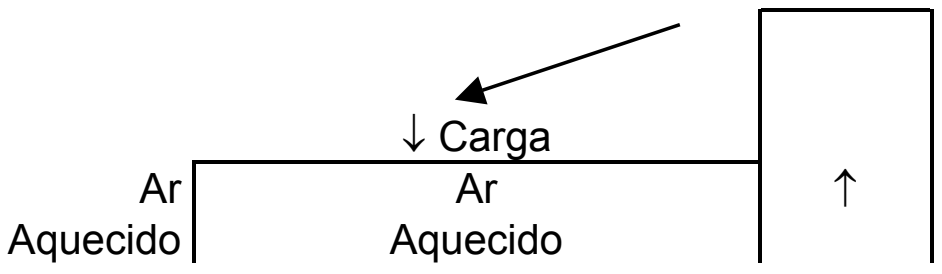




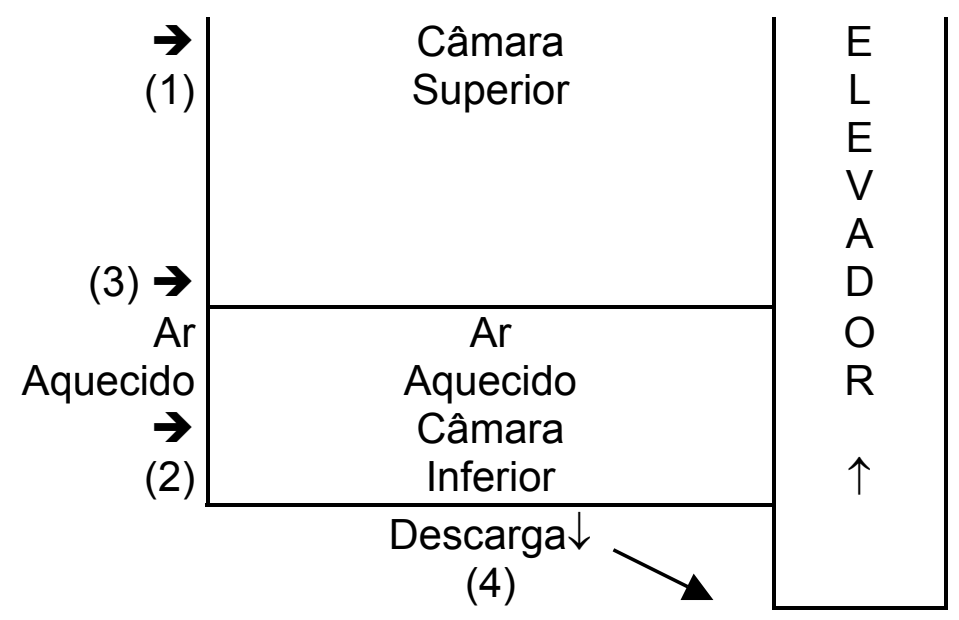

\section{FIGURA 2 - Secagem contínua: esquema operacional do secador utilizado e dos pontos de amostragem.}

No processo de secagem intermitente rápida e contínua, para a determinação da qualidade física, fisiológica e sanitária, foram tomadas quatro amostras de quatro quilos. As amostras, excetuando-se as obtidas ao término da operação, passaram por secagem complementar em casa de vegetação fechada, até que fossem atingidos teores de água próximo a $13 \%$. As amostras iniciais (tempo zero) foram admitidas como testemunha (Test.) nas comparações entre os tratamentos (tempos de secagem).

Após estarem secas todas as amostras foram divididas em duas porções e embaladas em embalagens de tecido de algodão, para as análises laboratoriais que ocorreram em julho e outubro (armazenamento em condições não controladas de ambiente).

Foram realizadas as seguintes avaliações no Laboratório de Análise de Sementes:

a) temperatura da massa de sementes (imediata) obtida com um termômetro de mercúrio introduzido dentro de um copo de "isopor" com sementes no ato da retirada das amostras;

b) teor de água (imediato) obtido pelo método indireto, com um determinador de umidade marca "Universal" (aferido com o método da estufa a $105 \pm 3^{\circ} \mathrm{C}$ por $24 \mathrm{~h}$ );

c) determinação da pureza (Brasil, 5) e danos mecânicos (Dias e Barros, 7) realizados em julho;

d) qualidade fisiológica (julho e outubro) pelos testes de germinação (Brasil, 5) e frio sem solo (Dias e Barros, 7), para o vigor; e) qualidade sanitária (julho e outubro) pelo teste de sanidade em papel de filtro (Neegaard, 11).

$O$ delineamento experimental empregado foi o inteiramente casualizado, com quatro repetições. Além das análises de variância realizadas com os dados originais (Demétrio, 6), foram utilizadas regressões polinomiais $(P \leq 0,01)$, para a obtenção das curvas de secagem.

\section{Qualidade física}

\section{RESULTADOS E DISCUSSÃO}

Os dados referentes ao teor de água das sementes, temperatura do ar e da massa, durante a secagem nos secadores intermitente rápido e de fluxo contínuo, estão compilados na TABELA 1. Assim, verifica-se na FIGURA 3 que, à medida que foi ampliado o tempo operacional, a velocidade de secagem foi sendo reduzida, confirmando a progressiva demanda de energia para a remoção da água das sementes (Nellist e Hughes, 12). Porém, pode ocorrer de o teor de água ter uma tendência de queda constante, sendo caracterizado por equação linear (Villela e Silva, 18).

No secador de fluxo contínuo (C), a velocidade média de secagem (entre 17,9 e 12,9\%) foi de 1,1 ponto percentual por hora $\left(\mathrm{pph}^{-1}\right)$, sendo que nos primeiros 135 minutos a velocidade foi de $1,6 \mathrm{pph}^{-1}$, e posteriormente diminuiu para $0,7 \mathrm{pph}^{-1}$ (TABELA 1). Estes resultados estão de acordo com aqueles obtidos em secagem de sementes de milho, com ar a $60^{\circ} \mathrm{C}$ e velocidade média de 1,1 $\mathrm{pph}^{-1}$ (Pereira, 13).

TABELA 1 - Tempo de secagem (min.), teor de água (\%), temperaturas $\left({ }^{\circ} \mathrm{C}\right)$ do ar e da massa de sementes de milho, em secadores intermitente rápido (IR) e contínuo (C).

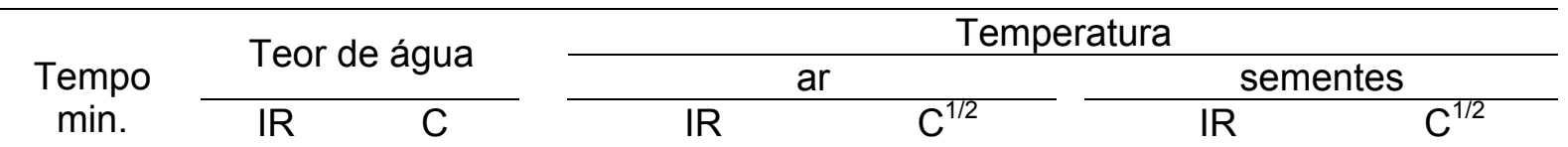




\begin{tabular}{lccccccc} 
& \multicolumn{2}{c}{} & & & & & \\
& Test. & 16,0 & 17,9 & 20 & $20 / 20$ & 20 & 21 \\
030 & 15,0 & - & 50 & - & 36 & - \\
045 & - & 16,3 & - & $40 / 30$ & - & $27 / 25$ \\
060 & 14,5 & - & 50 & - & 40 & - \\
090 & 13,9 & 15,5 & 60 & $50 / 40$ & 44 & $37 / 27$ \\
120 & 13,5 & - & 50 & - & 44,5 & - \\
135 & - & 14,4 & - & $60 / 50$ & - & $50 / 34$ \\
150 & 13,4 & - & 50 & - & 42 & - \\
180 & 12,9 & 13,8 & 40 & $60 / 50$ & 42 & $49 / 37$ \\
210 & 12,8 & - & 40 & - & 42 & - \\
225 & - & 13,2 & - & $50 / 40$ & - & $49 / 38$ \\
240 & 12,5 & - & 40 & - & 41,5 & - \\
270 & - & 12,9 & - & $45 / 40$ & - & $42 / 34$ \\
\hline C.V. & 0,88 & 1,04 & - & - & - & - \\
F & $* *$ & $* *$ & - & - & - & - \\
\hline
\end{tabular}

${ }^{(1)}$ câmara superior $\mathrm{e}^{(2)}$ câmara inferior de secagem.

** indica diferença significativa a $1 \%$ de probabilidade.

Na TABELA 1, para o secador de fluxo contínuo (C), constata-se que a temperatura máxima do ar de secagem atingiu $60^{\circ} \mathrm{C}$ (câmara superior) e $50{ }^{\circ} \mathrm{C}$ (câmara inferior) após 135 minutos operacionais. Estas permitiram atingir a temperatura máxima $\left(50^{\circ} \mathrm{C}\right)$ das sementes na câmara superior; na câmara inferior, contudo a temperatura máxima $\left(38^{\circ} \mathrm{C}\right.$ ) ocorreu após 225 minutos operacionais.

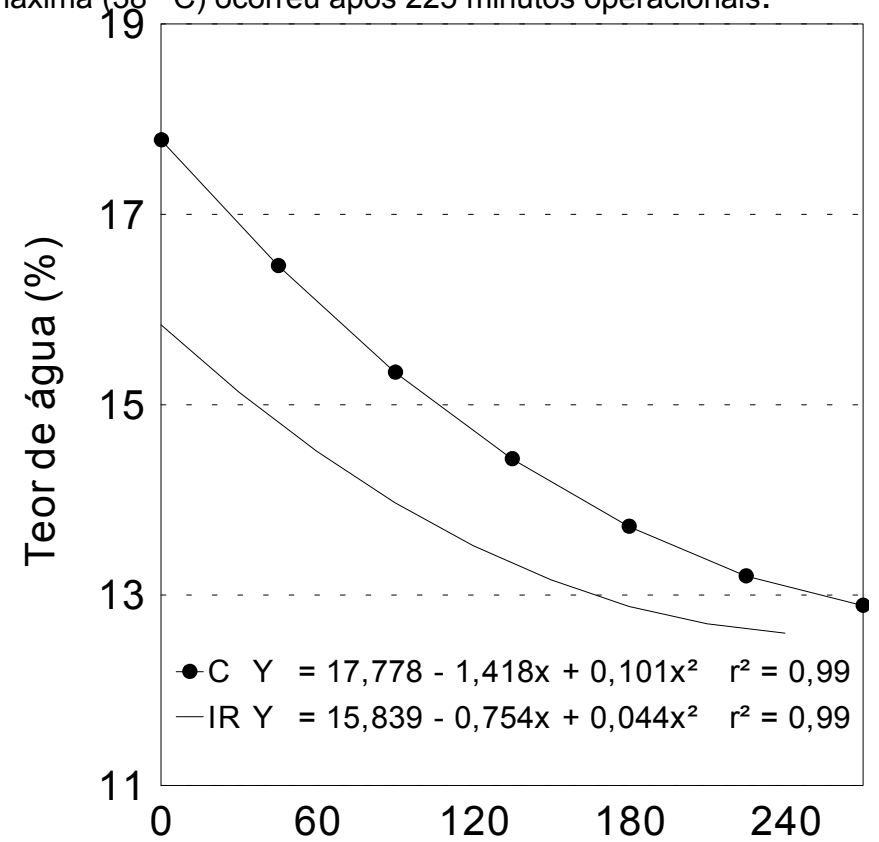

FIGURA 3 - Curvas de secağemnqoo \$emiențesedeerałberAPAR 51, empregando secadores contínuo (C) e intermitente rápido (IR).

A velocidade média de secagem no secador intermitente rápido (IR) foi de $0,9 \mathrm{pph}^{-1}$, entre teores de água de 16 a $12,5 \%$. Durante a primeira hora a velocidade foi de $1,5 \mathrm{pph}^{-1}$, reduzindo-se, posteriormente para $0,7 \mathrm{pph}^{-1}$. Ahrens et al. (2), empregando o mesmo secador e temperatura do ar, obtiveram velocidade de 1,7 $\mathrm{pph}^{-}$ ${ }^{1}$ entre teores de água de 22 a 12,7\%. A temperatura do ar de secagem (TABELA 1) atingiu o máximo de $60^{\circ} \mathrm{C}$, enquanto que a temperatura da massa alcançou $44,5^{\circ} \mathrm{C}$, reduzindo de modo gradativo com a queda da temperatura.

A pureza e a taxa de danos mecânicos não apresentaram diferenças significativas durante a secagem, em ambos os secadores testados (TABELA 2). Esta indicação sugere a ausência de 
efeitos físicos sobre as sementes oriundas, especialmente, do transporte de carga e descarga dos secadores. Possivelmente, problemas ocorridos na colheita (teor de água das sementes, tipo de regulagem na colhedeira, entre outros) proporcionaram este elevado percentual de danos, em maior número para o lote secado pelo processo contínuo. Para Villela (17) a média de danos apresentados em seu trabalho foi de $16,3 \%$.

TABELA 2 - Pureza (\%) e danos mecânicos (\%) de semente de milho IAPAR 51 submetidas às secagens pelo processo intermitente rápido (IR) e contínuo (C).

\begin{tabular}{|c|c|c|c|c|}
\hline \multirow{3}{*}{$\begin{array}{c}\text { Tempo } \\
\text { min. }\end{array}$} & \multicolumn{2}{|c|}{ Pureza } & \multicolumn{2}{|c|}{ Danos } \\
\hline & IR & $\mathrm{C}$ & IR & C \\
\hline & & & & \\
\hline Test. & 97,8 & 97,9 & 37 & 44 \\
\hline 060 & 98,4 & - & 36 & - \\
\hline 090 & - & 97,8 & - & 42 \\
\hline 120 & 98,5 & - & 36 & - \\
\hline 180 & 98,0 & 97,8 & 39 & 45 \\
\hline 240 & 98,1 & - & 36 & - \\
\hline 270 & - & 97,5 & & 46 \\
\hline C.V. & 0,4 & 0,3 & 12 & 8 \\
\hline$F$ & ns & ns & ns & ns \\
\hline
\end{tabular}

ns - indica ausência de significância ao nível de 1\% de probabilidade.

Qualidade fisiológica

A avaliação da qualidade fisiológica não indicou variações significativas entre os tempos de secagem nos secadores, inclusive após 0 armazenamento (TABELA 3), confirmando os valores obtidos por Ahrens et al. (2). Villela (17) e Pereira (13) também não observaram reduções na qualidade fisiológica de sementes de milho submetidas a secadores contínuos adaptados e de fluxo contínuo, respectivamente.

TABELA 3 - Germinação (\%) de sementes de milho IAPAR 51 submetidas à secagem intermitente rápida (IR) e contínua (C), em duas épocas.

\begin{tabular}{|c|c|c|c|c|}
\hline \multirow{3}{*}{$\begin{array}{c}\text { Tempo } \\
\text { min. }\end{array}$} & \multicolumn{2}{|c|}{ IR } & \multicolumn{2}{|c|}{ C } \\
\hline & Jul. & Out. & Jul. & Out \\
\hline & & & & \\
\hline Test. & 95 & 95 & 84 & 84 \\
\hline 060 & 95 & 93 & - & - \\
\hline 090 & - & - & 88 & 85 \\
\hline 120 & 94 & 91 & - & - \\
\hline 180 & 95 & 91 & 87 & 84 \\
\hline 240 & 93 & 94 & - & - \\
\hline 270 & - & - & 81 & 82 \\
\hline $\mathrm{CV}$ & 1,4 & 2,4 & 4,6 & 4,9 \\
\hline $\mathrm{F}$ & ns & ns & ns & ns \\
\hline
\end{tabular}

ns - indica ausência de significância ao nível de $1 \%$ de probabilidade.

TABELA 4 - Vigor (\%) de sementes de milho IAPAR 51 submetidas à secagem intermitente rápida (IR) e contínua (C), em duas épocas de avaliação. 


\begin{tabular}{cccccc}
\hline & & IR & & \multicolumn{2}{c}{ C } \\
\cline { 2 - 3 } \cline { 5 - 6 } Tempo & Jul. & Out. & $\%$ & Jul. & Out. \\
\hline Teist. & 91 & 92 & & 79 & 78 \\
060 & 90 & 90 & - & - & - \\
090 & - & 92 & & 78 & 82 \\
120 & 92 & 89 & & - & - \\
180 & 93 & 91 & - & - \\
240 & 93 & - & 78 & 75 \\
270 & - & 2,2 & & 4,0 & 4,7 \\
CV & 2,0 & ns & ns & ns \\
F & ns & & & & \\
\hline
\end{tabular}

ns - indica ausência de significância ao nível de 1\% de probabilidade.

\section{Qualidade sanitária}

Observou-se alta incidência Penicillium spp. durante os dois processos de secagem. Isto pode ser explicado pelo fato desse fungo invadir as sementes antes da colheita (Pinto, 14), por se tratar de fungo intermediário (Lázzari, 10). Na secagem

TABELA 5 - Dados médios de Penicillim spp. (\%) obtido em sementes de milho IAPAR 51 submetidas às secagens pelo processo intermitente rápido (IR) e contínuo (C), em duas épocas de avaliação. intermitente rápida (IR) a incidência de Penicillium spp., em julho (TABELA 5), revelou diferenças significativas. Possivelmente este fato ocorreu em função dos valores dos tratamentos intermediários terem sido inferiores aos demais.

\begin{tabular}{|c|c|c|c|c|}
\hline & \multicolumn{2}{|c|}{ IR } & \multicolumn{2}{|c|}{ C } \\
\hline & Jul. & Out. & Jul. & Out. \\
\hline & \multicolumn{4}{|c|}{$\%$} \\
\hline Test. & $93 a$ & 98 & 96 & 95 \\
\hline 060 & 92 a & 88 & - & - \\
\hline 090 & - & - & 95 & 96 \\
\hline 120 & $86 \mathrm{~b}$ & 86 & - & - \\
\hline 180 & $86 \mathrm{~b}$ & 96 & 98 & 86 \\
\hline 240 & $90 \mathrm{ab}$ & 96 & - & - \\
\hline 270 & - & - & 96 & 96 \\
\hline $\mathrm{CV}$ & 3 & 7 & - & - \\
\hline $\mathrm{F}$ & $* *$ & ns & - & - \\
\hline
\end{tabular}

ns - indica ausência de significância ao nível de 1\% de probabilidade.

Durante a secagem pelo processo intermitente, apesar da significância, observa-se que entre a testemunha (Test.) e o tratamento final (240 min.) praticamente não houve redução do fungo (TABELA 5). Estes resultados discordam de Villela (17), que conseguiu uma redução de Penicillium spp. durante a secagem, mas usando temperatura de 70,80 e $90^{\circ} \mathrm{C}$, de forma que o ar aquecido pode ter proporcionado um tratamento térmico às sementes. Mas este método, de acordo com Lasca (9) e Soave e Moraes (16), possui baixa eficiência, por não ter efeito residual e possibilitar menor troca de calor em relação a outros tratamentos. Na secagem contínua não houve redução do percentual de sementes infectadas com Penicillium spp., como verifica-se na TABELA 5. 
Por tratar-se de um volume relativamente grande $(15 t+4 t)$ para secar-se, não foi possível trabalhar com o mesmo lote em ambos os secadores, o que resultou em qualidades físicas e fisiológicas distintas, mas que não interferiu nos processos de secagem. Assim não foram feitas comparações entre os dois secadores.

\section{CONCLUSÕES}

- Os secadores fluxo contínuo e intermitente rápido são eficientes na secagem de milho com altas temperaturas;

- Não há comprometimento das qualidades física e fisiológica das sementes submetidas à secagem contínua e intermitente rápida, empregando-se as temperaturas no ar de secagem de $600^{\circ} \mathrm{C}$ e $60 / 500^{\circ} \mathrm{C}$, respectivamente;

- Nas temperaturas utilizadas, os processos de secagem não reduzem a infestação de Penicillium.

\section{AGRADECIMENTOS}

Os autores agradecem aos Engenheiros Agrônomos Egon Hinsching e Josemar Wambier, da CODAPAR e ao Técnico Agrícola Aldo L. Figueiredo, do IAPAR, pela colaboração prestada na instalação dos experimentos.

\section{REFERÊNCIAS}

1. AHRENS, D.C.; PESKE, S.T. Flutuações de umidade e qualidade de semente de soja após a maturação fisiológica. I. Avaliação do teor de água. Revista Brasileira de Sementes, Brasília, v.16, n.2, p.107-110. 1994.

2. AHRENS, D.C.; BARROS, A.S.R.; VILLELA, F.A.; LIMA, D. Qualidade de sementes de milho (Zea mays L.) durante a secagem em secadores intermitentes lento e rápido. In: CONGRESSO NACIONAL DE MILHO E SORGO (XXI: Londrina, 1996). Anais. Londrina, p. 230, 1996.

3. AHRENS, D.C.; LOLLATO, M.A. Qualidade de semente de feijão e velocidade de secagem ao sol e em secador intermitente. Revista Brasileira de Sementes, Brasília, v.19, n.1, 1997.

4. AHRENS, D.C; VILLELA, F.A. Secagem intermitente $e$ seus efeitos na qualidade fisiológica de sementes de tremoço azul. Scientia Agricola, v. 53, n. 2/3, p. 309-315, 1996.

5. BRASIL, Ministério da Agricultura e Reforma Agrária. Regras para Análise de Sementes, Brasília, SNAD/DNDV/CLAV, 1992. 365 p.
6. DEMÉTRIO, C.G.B. Transformação de dados: Efeitos sobre sua análise da variância. Piracicaba: 1978. 113f. Dissertação (Mestrado em Estatística) - Escola Superior de Agricultura "Luiz de Queiroz" - Universidade de São Paulo.

7. DIAS, M.C.L.L.; BARROS, A.S.R. Avaliação da Qualidade de Sementes de Milho. Londrina, IAPAR, 1995. 43 p. (Circular 88).

8. GUSTAFSON, R.J.; MOREY, R.V. Study of factors affecting quality changes during high temperature drying. Transactions of the ASAE, St. Joseph, v. 22, n. 4, p.926-932, 1979.

9. LASCA, C.C. Tratamento de sementes. In: Simpósio Brasileiro de Patologia de Sementes (2.: Campinas: 1986). Anais. Campinas: Sociedade Brasileira de Patologia de Sementes, 1986, p.93-99.

10. LÁZZARI, F.A. Umidade, Fungos e Micotoxinas na Qualidade de Sementes, Grãos e Rações. Curitiba: F.A. Lázzari, 1993. 140 .

11. NEEGAARD, P. Seed pathology. London: Mac Millan Press, v. 1, 1979. 839p.

12. NELLIST, M.E; HUGHES, M. Physical and biological process in the drying of seed. Seed Science and Technology, Zurich, v. 1, n.3, p.613-643, 1973.

13. PEREIRA, F.T.F. Efeito da Secagem Intermitente na Qualidade de Sementes de Milho. Pelotas: 1991. 92f.Dissertação (Mestrado em Agronomia) - Faculdade de Agronomia "Eliseu Maciel" da Universidade Federal de Pelotas.

14. PINTO, N.F.J.A. Tratamento fungicida de sementes de milho. In: SIMPÓSIO BRASILEIRO DE PATOLOGIA DE SEMENTES (4.: Gramado: 1996). Anais. Gramado: Sociedade Brasileira de Patologia, 1996 , p. 52-57.

15. PUZZI, D. Manual de Armazenamento de Grãos: Armazéns e Silos. Ceres: São Paulo, 1977. 405p.

16. SOAVE, J.; MORAES, S.A. Medidas de controle das doenças transmitidas por sementes. In: SOAVE, J., WETZEL, M. M. V. S. Patologia de sementes. Campinas: Fundação Cargill, 1987, p. 192-259.

17. VILLELA, F.A. Efeitos da Secagem Intermitente sobre a Qualidade de Sementes de Milho. Piracicaba: 1991. 104f. Tese (Doutorado em Agronomia) - Escola 
Superior de Agronomia "Luis de Queiroz" Universidade de São Paulo.

18. VILLELA, F.A.; SILVA, W.R. da . Curvas de secagem de milho utilizando o método intermitente. Scientia Agrícola. Piracicaba, v. 49, n.1, p.145-153, 1992.
19. WETZEL, M.M.V.S. Fungos de armazenamento. In: SOAVE, J.; WETZEL, M.M.V.S.(Ed.) Patologia de sementes. Campinas: Fundação Cargill, 1987, p.260-275. 